\title{
The Research of Construction of Sport Fitness Service Quality Evaluation System
}

\author{
Lijuan Zhang \\ Department of Physical Education Research, Henan University of Traditional Chinese Medicine, \\ Boxue Road, East Jinshui Road, Zhengzhou City 450008,China
}

Keywords: Business Sports Fitness Centers; Quality of service; Evaluation System.

\begin{abstract}
By methods of literature, questionnaire, Delphi, we surveyed operating sport fitness places and consumers survey in Zhengzhou. On the basis of expert advice, we gave the operating Sports Fitness Centers Service Quality Evaluation System, used AHP method to determine the every index weight of the index system, and analyzed them.
\end{abstract}

\section{Introduction}

In recent years, as China's "fitness" business continues to advance, the value of health and special protecting features of life quality in fitness sports hosted in its care, improvement, and supervisor have got unprecedented excavation and identity, and with the rapid development of national economy and improvement of people's income, "spending money on health" has become a trend. According to statistics, the average annual household sports consumption in Guangdong Pearl River Delta region has been more than 2100 Yuan, accounting for the $6 \%$ of family revenues [1], and sports and fitness consumption has become a new hot spot at this stage of the developed areas of the consumer. Faced with such a huge market, operating sports and fitness venues have sprung up. The research shows that China's current actual operating conditions of operational sport Fitness centers is not optimistic, and because of the lack of standardization research of operational sport fitness centers, our optional sports fitness areas development is not balanced; high and low operational sport fitness places are with serious polarization; and payback time of their cost is long with generally bad economic efficiency [4].The reasons for this phenomenon are many: the low total amount of the national economy, the low people economic income people, poor awareness of consumer fitness and so on. But the most important reason is the low quality service system of operational fitness sport places, resulting in often there is a big gap between the expectations of psychological services provided by operators and consumers, and therefore cannot produce enough attractiveness to fitness consumers . To solve this problem, we made a questionnaire for fitness consumers and operators of Zhengzhou as the survey sample questionnaire, and on the basis of expert advice, we given on their quality of service indicator system and carried out evaluation analysis to promote standardization of service Quality system of commercial fitness sport places.

\section{Research Methods}

\section{1 literature}

Consult related research from 1990 to 2006 such as "Sports Science", "China Sport Science and Technology", "marketing", "quality of service", "full-service quality management", SPORT MARKETING magazine, collect and manage the relative research results of services quality evaluation index of commercial sports fitness places, and after screening and sorting, obtain 89 evaluation index. And design consumer questionnaire.

\section{2 questionnaire}

Make a questionnaire for sport fitness consumers and operators of the counties in Zhengzhou. Regarding operational fitness centers provided by its Sports Bureau as the sampling frame, collecting samples by classification, stratification, snowball, quota sampling method, and regarding sport programs as a basis for classification, we can extract stratified samples of commercial fitness sport 
centers according to the size and grades. For consumers using accidental sampling survey, we distributed the questionnaire to respondents by the interviewer let them fill out and back. Deal with The recovered questionnaires and cancel invalid questionnaires. A total of 375 questionnaires were sent out, 341 copies are send back with excluding 9 invalid questionnaires and 332 valid questionnaires. The recovery rate was $88.5 \%$.

\subsection{Mathematical Analysis}

Use SPSS10.0 software to analyze the results of the consumer survey. Delete indexes of the smaller importance of statistics, such as the "reception area", "fashion fitness programs" and other eight indexes and obtain an evaluation index system of six first indicators, 20 secondary indicators and 81 third indicators.

\subsection{Delphi method}

Make an investigation for experts about the initial established service quality evaluation System and the subject of investigations involves 10 sport human sociology professors at the 8 universities; six people are in charge of sports industry department , and all kinds of operational fitness centers operators are 9 , accounting for a total of 25 people. The expert quality of representativeness, authority, hierarchy are in line with the requirements of the Delphi Method.

Follow the theoretical basis of the indicator design, conclude and summarize the findings of two round to enable experts to converge at all levels of the selection of indicators (opinions concentration ratio is over 90\%) and to finalize the evaluation indicator system of Service Quality of commercial sports fitness centers .

\subsection{Analysis Hierarchy Process (AHP)}

Determine the evaluation index weight coefficient by using the analytic hierarchy process, and make evaluation and analysis of the index system [5, 6].

\section{Results and Analysis}

\subsection{Service Quality Index System analysis of commercial sport fitness places}

\subsubsection{Quality of sport fitness instructor is the first element in the evaluation of quality of service}

It is not difficult to see from Table 1 that in the four first indicators, the quality weight of the sport fitness instructors (0.393) is maximum and far more than the other indexes, being a most important factor in service Quality Indicator system of sport fitness places. The indicators include 4 secondary indicators of athletic ability, organizational skills, and responsibility and communication skills of sport fitness instructors. Here athletic ability of fitness instructors that whether they receive professional training on the project and master the project system knowledge and the rules, is secondary indexes with the highest weight value (0.402). In addition, the communication skills of sport fitness instructor also occupies a very important position (weighted value of 0.271 ). The evaluation results, to some extent, reflect the rational tendency of our physical fitness consumption.

Sports Fitness service is undoubtedly a "import". And from our survey of business Sports Fitness Places, we can see that either the provider of the project or the layout of the place all follow the foreign practices. It is not difficult to imagine when the novelty came to China, the first to attract people's attention will be novelty items and a variety of fitness equipment. The people understanding for Sports fitness centers are only limited in forms, and motivation of participants in large part is due to its fashion. So fitness consumption in those places is filled with a lot of irrational colors.

With the rapid increase in the number of fitness sites and people are familiar with various fitness programs and exercise equipment, the evaluation criteria of operational Sport Fitness Service Quality fitness in their minds also changed - reason gradually replaced the irrational, attention is diverted from the "objects" of curiosity to the "service" requirements and physical fitness body functions become the focus of attention. The fitness instructors, as the most direct physical fitness service providers whose own quality assure to provide reasonable and scientific health services or not, are also bound to be greatly concerned by consumers, operators and experts. In addition, in recent years with the rapid development of China's sports industry, hardware facilities of commercial sports fitness places including the venue, lighting, fitness equipment, etc. in function, safety, appearance, 
and on the degree of modernization has reached a higher level to meet the basic needs of consumers, which is one of the reasons of the experts and consumers pay attention to "software" service.

Given by the Index System of experts compared to the Index System obtained by fitness investigations, in the former index system, the fitness instructor quality weight value is significantly higher than the latter. Differences between expert advice and consumer survey results is derived from their different positions: consumers are concerned about personal feelings and physical and mental satisfaction he got in the process of physical fitness, and evaluation index selection and evaluation of experts are based on the perspective of the whole industry more healthy development. From a macro point of view, the impact of expert advice on fitness places is more far-reaching.

\subsubsection{Analysis of fitness activities set indicators}

Fitness activities set indicators include three secondary indicators of project settings, fitness content, and project updates. Survey shows that in recent years, awareness of this indicator has also undergone a significant change from in the past few years the most concern about the project's novel, unique and ever-changing to the inherent value of the project itself. In addition to the fitness function of the required project, whether the project has a social function and whether is appropriate for the entire family to participate and exercise together to enhance interaction between family and friends have become the focus of attention, this new changing need trend should cause the operator's enough attention.

\subsubsection{Price and fitness schedule Index Analysis}

Studies have shown that fitness consumer price is a more subtle index in the service quality index system. In the high-grade, charge-relatively high places, prices are often not the main basis that consumers choose or evaluate the quality of service places, while in the low-cost options, consumers are more sensitive to the issue price, and often choose it as a more important basis of a place of fitness. It shows commercial Sports Fitness Centers of different specifications have more differences in corresponding to the market and consumer groups, and the operators should give enough attention to this difference in market positioning.

\subsubsection{Analysis of social effectiveness indicators}

Although social profits of sport fitness sites is secondary indicator throughout the service quality index systems, it is a new trend in this system, so experts and consumers both have given considerable attention. For consumers, some professional game tasks and relevant social welfare activities of commercial sports fitness centers often indicate that it has a strong professional and authoritative essence and has the ability to provide a more comprehensive health services, so they will be more inclined to choose this type of fitness sites. For specialists, commercial sports fitness centers participate in social activities, improve social influence and can continue to attract more people to participate in fitness activities, which creates a favorable external environment for "all-people fitness enterprise" and the whole market orderly development of commercial sports fitness centers and thus shows keen interests in this indicator.

\section{Conclusion}

Service quality is an extremely important factor affecting operating Sports Fitness Centers develop and to enhance the standardization research of Operation Sports Fitness Centers Service Quality Index System is imperative.

Quality of fitness instructor is the most important indicator of Commercial Sports Fitness Places service quality. This is an inevitable choice for health consumers from the irrational consumption to the rational consumption.

Whether Fitness programs have social features and are suitable for the entire family to participate and exercise together to enhance interaction between family and friends is being paid to more and more attention and should attract the operator's attention.

The social profits of Commercial social Sports Fitness Centers is a new content of the service quality indicators, so experts and consumers both have given considerable attention, which is a new direction of the study of the service quality of Commercial Sport Fitness centers in china. 


\section{References}

[1] Yu Junbiao, etc. Survey and Analysis on current institutions of sport consumption and sports Industry of XiaMen [J], sports science, 2012.7

[2] Luo Bingquan Research about Beijing Mass Sports Industrialization. [J], sports science, 2012.2

[3] Zhu Li,etc. The ideals and ways about the western development of sports industry [J], sports science, 2012.3

[4] Luo Bingquan, etc. Discussion of some problems of sport market development in china [J]. Sports and Science, 2011.7

[5] Shao Guihua, Sun Zhuqing. Study of PE graduate students' creative ability index system and its evaluation methods [J]. Sports Science, 2014.6

[6] Sun Qingzhu, Research about teacher PE Students' Comprehensive Ability Training of and establishment of multivariate evaluation mathematical model, sports science [J] 2014.6

[7] Liu Tao.Study of current Mass Sports Service Quality Evaluation Factors [J]. Journal of Yunnan University of Finance, 2015.12 